\title{
Videometry studies of left ventricular wall movement after myocardial infarction
}

\author{
G. R. Sutherland, A. L. Evans, M. Davison, and J. Kennedy \\ From the Department of Radiology, Southern General Hospital, Glasgow; \\ and the Department of Clinical Physics and Bio-Engineering of the Western Regional Hospital Board
}

\begin{abstract}
Investigations using videometry were made on 15 normal subjects and 20 patients with previous myocardial infarction; videometry is a new radiological method of measuring the amplitude and rate of displacement of the left ventricular wall. Videotape recordings of the movement of the left heart border as seen on a conventional image intensifier television screening set are made simultaneously with a record of the electrocardiogram. The videometer is used to analyse the movements of the image of the left ventricle at 5 positions along its length in the posteroanterior, left anterior oblique, and lateral projections. Abnormalities of movement amounting to dyskinesia or paradox vere commonly found, in addition to an overall reduction in amplitude and rate of systolic displacement in the abnormal group. Unexpectedly, two of the normal subjects also showed dyskinetic activity at the apex and a hypothesis is proposed to explain the phenomenon.
\end{abstract}

Since the 1930's, cardiologists and radiologists have attempted to record the extent of movements of the left heart border. Simple fluoroscopy (Master et al., 1940), $x$-ray kymography (Crawford and Gubner, 1938; Gubner and Crawford, 1939; Hirsch, 1934), electrokymography (Henny and Boone, 1945; Sussman, Dack, and Paley, 1949; Bartley, 1960), cinefluoroscopy (Kurtzman and Lofstrom, I963), and cineangiography (Herman et al., 1967; Gorlin, Klein, and Sullivan, 1967) have all been used as methods of making this assessment. Because of technical inadequacy, $x$-ray and electrokymography rapidly lost favour; simple fluoroscopy, particularly after the advent of image intensification, became the most frequently used method, but the subjective nature of the assessment and the lack of a permanent record limit its usefulness. Cinefluorography, though producing a permanent record, is also subject to observer bias. At the present time, cineangiography may be regarded as the standard method of obtaining topographical information about the left ventricle, but its use is restricted by the need for left ventricular catheterization in patients who are almost invariably seriously ill. In 1968, Cohen et al. described the use of a new technique based on an image intensifier television screening system which they called radar kymography, and subsequently in 1971, Kazamias et al.

Received I January 1973. described the detection of abnormalities of left ventricular wall movement using this technique.

Videometry is a similar technique which we have developed which permits measurement of amplitude and rate of displacement of the left ventricular wall in addition to producing an analogue display of cardiac movement. The present paper describes our preliminary experience with the method in normal subjects and patients with coronary artery disease.

\section{Principle of the method}

Videometry is a method of measuring the motion of the heart demonstrated on the TV monitor of a conventional image intensifier television system. Its operation depends on the following principle. A television picture is composed of a series of horizontal scan lines of varying brightness. At the edge of the image of the heart (Fig. I A), a voltage change occurs on the scan lines corresponding to the change in brightness and this is made to trigger a comparator circuit in the videometry signal processor which determines the position of the voltage change and measures its distance from a fixed reference point (Fig. I B). This process is carried out continuously on a number of scan lines selected to cover approximately $\mathrm{I} \mathrm{cm}$ in height on the television picture, and effectively registers the motion of the heart border in a linear fashion. The position at which the measurement is being made and the reference points are identified as bright lines (Fig. 2) and can be moved together to any part of the television picture. 


\section{Method of recording and analysis}

The investigations were carried out with the subject in the supine position on a conventional image intensifier television screening set (Fig. 3). Videotape recordings, ro-I5 sec in length, of the movement of the left ventricular margin were made on an Ampex VR 7003 recorder in mid inspiration with the subject in the posteroanterior, $30^{\circ}$ left anterior oblique, and left lateral projections. At the same time, the electrocardiogram (lead I) was recorded on one of the audio channels of the recorder. In order to minimize distortion, the left heart border was carefully positioned in the centre of the image intensifier field. Calibration of the system was obtained by recording the movements of a copper sheet placed in the $x$-ray beam, $15 \mathrm{~cm}$ above the screening table as it was advanced in $0.5 \mathrm{~cm}$ increments over a distance of $2.5 \mathrm{~cm}$. $X$-ray screening factors were $90 \mathrm{Kv}$ and $0.5 \mathrm{~mA}$.

Videometry analysis of the recordings of left ventricular movement was subsequently made by replaying the videorecording with the videometry measurement markers placed at 5 positions (Fig. 4) at approximately $\mathrm{I} \cdot 5$ $\mathrm{cm}$ intervals along the left ventricular margin in the posteroanterior and oblique projections. In the lateral projection usually only 2 or 3 positions could be studied as the image of the heart merged with the diaphragm or mediastinal structures. The displacement of the calibrating copper sheet was analysed in a similar manner. The output from the videometer and the replayed electrocardiogram were recorded simultaneously on a Bell and Howell ultraviolet oscillograph and subse-

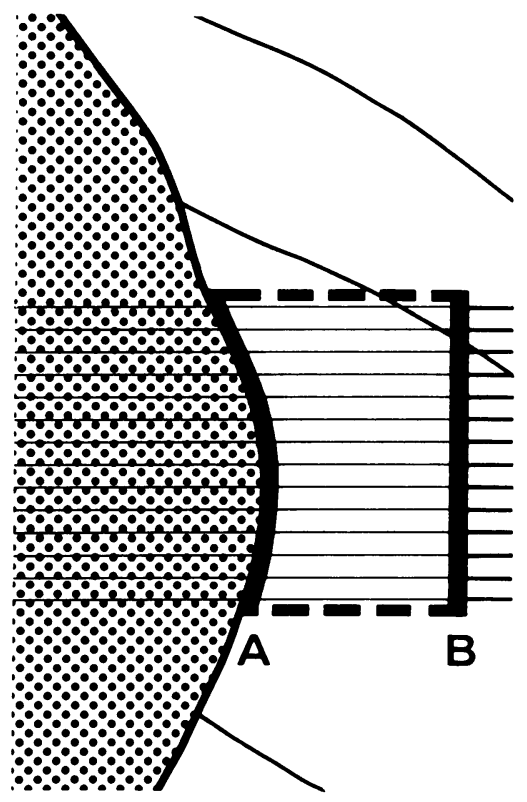

FIG. I Diagram of the magnified TV image of the apical area of the heart (dotted area) with the videometry measurement markers (' $A$ ' and ' $B$ ') in position.

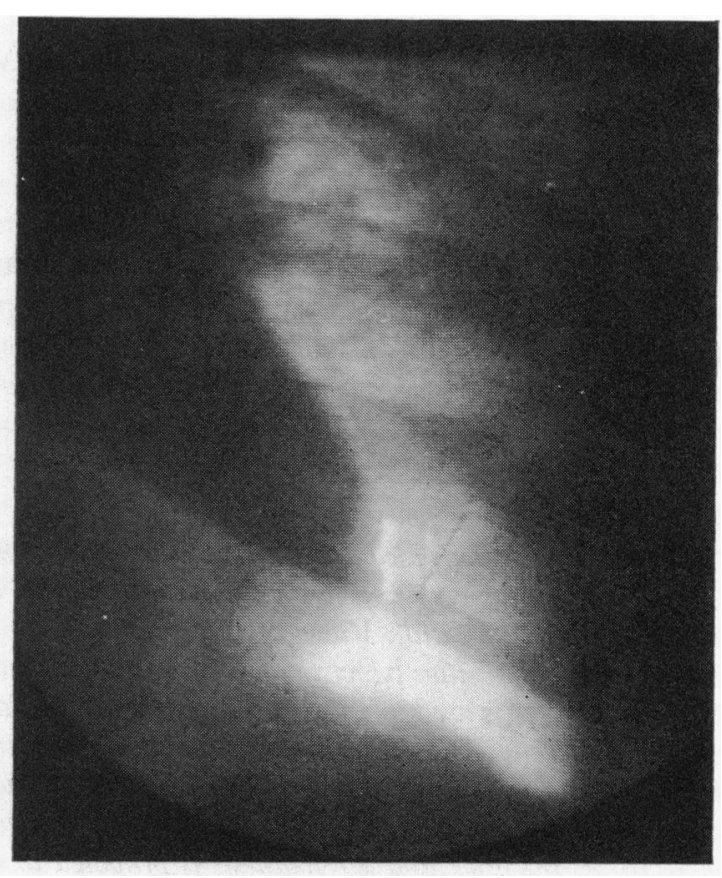

FIG. 2 Photograph of TV monitor showing the videometry markers (bright lines) in relation to the apex of the heart.

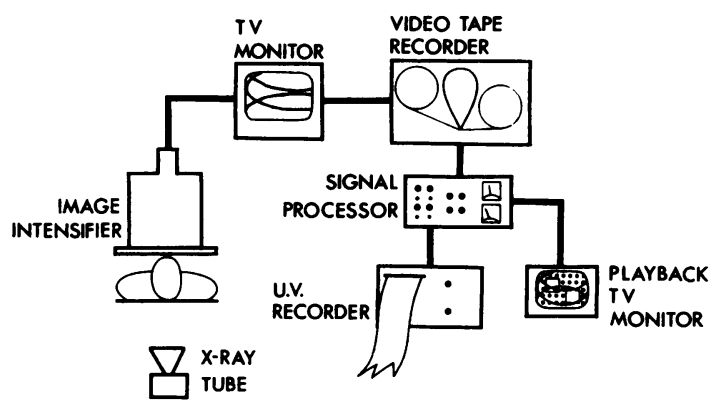

FIG. 3 Diagram of arrangement of the apparatus. Videotape recordings of the heart movements are replayed through the videometer (signal processor unit) which produces an analogue signal recorded by the UV oscillograph.

quently average measurements were made of the amplitude and maximum rate of systolic displacement of the heart border during 4 consecutive cycles at each position in each of the 4 projections.

\section{Subjects}

Fifteen normal subjects ( 13 men, 2 women), with a mean age of 35 years (range 22 to 58), and 20 patients 


\section{NOPMAL}
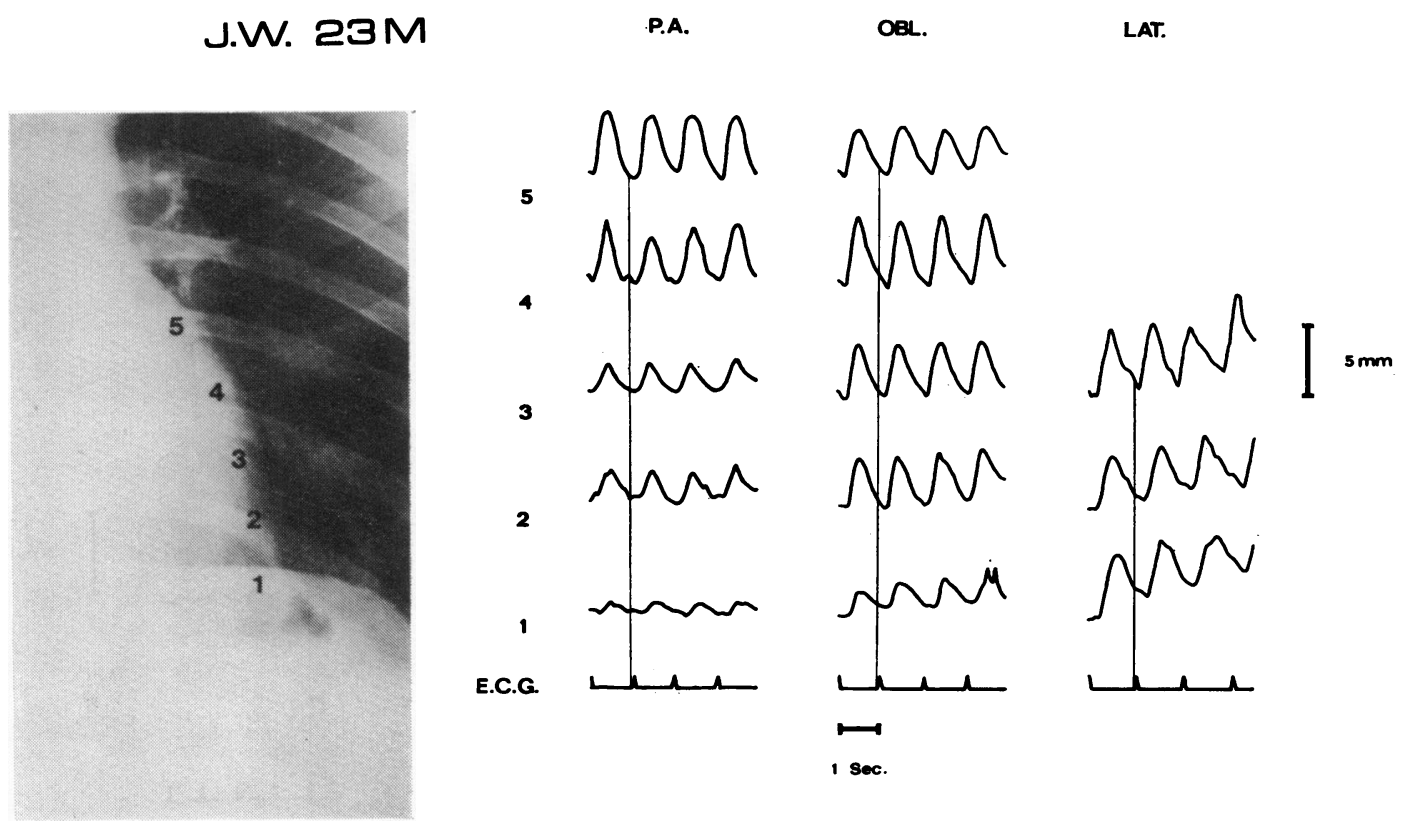

FIG. 4 Normal videogram showing the five positions on the left heart border at which measurements are made in the PA and oblique projections. An upward displacement of the traces indicates systolic movement.

with severe coronary artery disease ( 17 men, 3 women), with a mean age of 53 years (range 32 to 68 ), were studied. Fourteen of the patients had suffered acute myocardial infarction approximately two weeks before and the remainder had a history of infarction 3 to 6 months before the investigation. Several of the patients were receiving treatment for left ventricular failure but none showed clinical or radiological signs of it at the time of the study. A standard 12-lead electrocardiogram was carried out in all patients and the normal subjects and serum aminotransferase determinations were made during the initial phase of the episode of infarction in all the patients.

\section{Results}

In Fig. 4 the videometry traces obtained from a normal subject are shown, upward displacement of the trace representing systolic movement. The normal relation of the electrical to the mechanical activity of the heart is clearly shown. Fig. 5 illustrates the appearances obtained in a patient with severe infarction. The electrocardiogram suggested an anteroseptal location and the asparate aminotransferase was raised to 250 units. The videogram shows extensive areas of reduced amplitude and rate of contraction. In the $I$ and 2 positions in the posteroanterior and the $I$ position in the oblique projection there is evidence of paradoxical or dyskinetic movement (Gorlin et al., 1967) due to failure of contraction. It is interesting to note the disparity between the normal electrocardiogram tracings from the posterior and inferior aspects of the heart, and the videogram from these areas, which shows widespread and severe abnormality (Dack, Sussman, and Master, 1940). The videogram shown in Fig. 6 illustrates the results obtained in a patient with extensive lateral and posterolateral infarction. In this case the appearances are those of relative immobility of the left ventricular wall (akinesis), indicating partial contraction of the muscle, sufficient to prevent its outward displacement by the action of the relatively normal remaining parts of the ventricle. These two cases illustrate the ease with which an objective assessment of the extent and severity of damage after myocardial infarction can be made and confirm the observations of Kazamias et al. (I97I). 


\section{ANTERO - SETTAL INFARCTION}

W.E. G1M

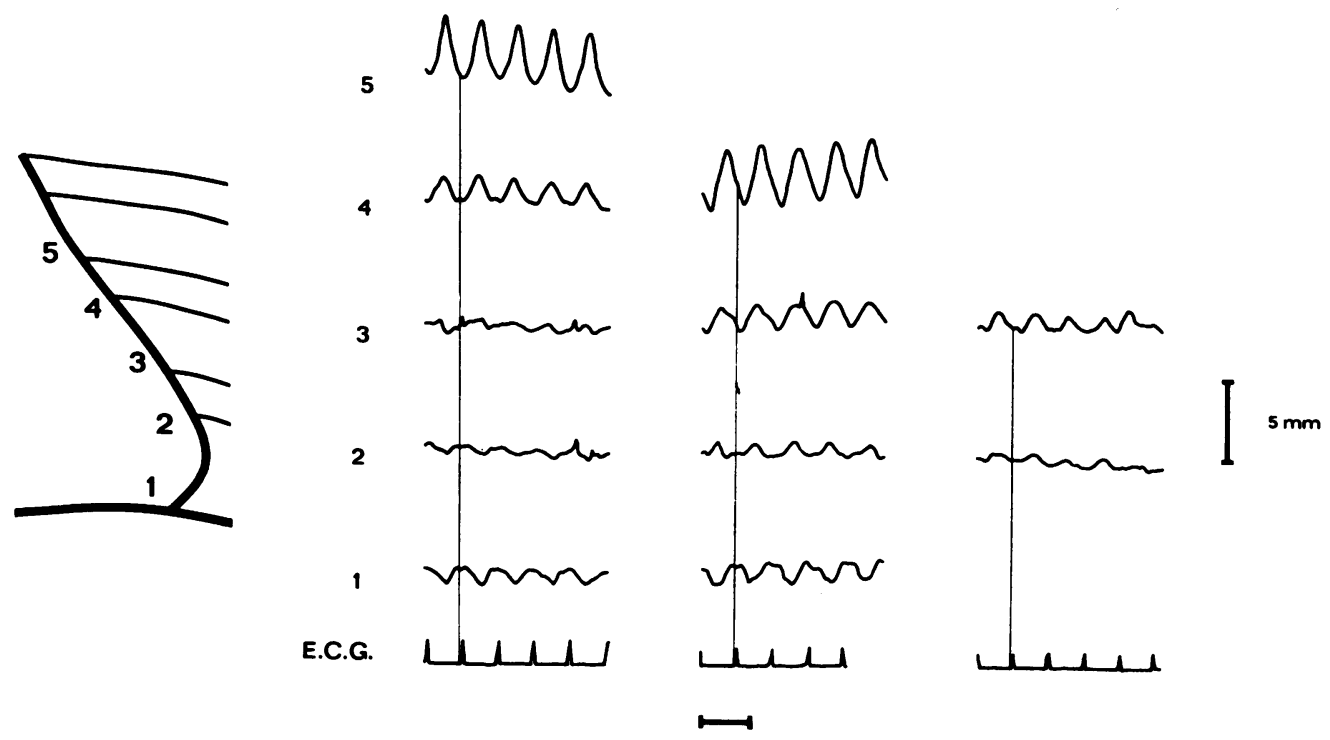

P.A.

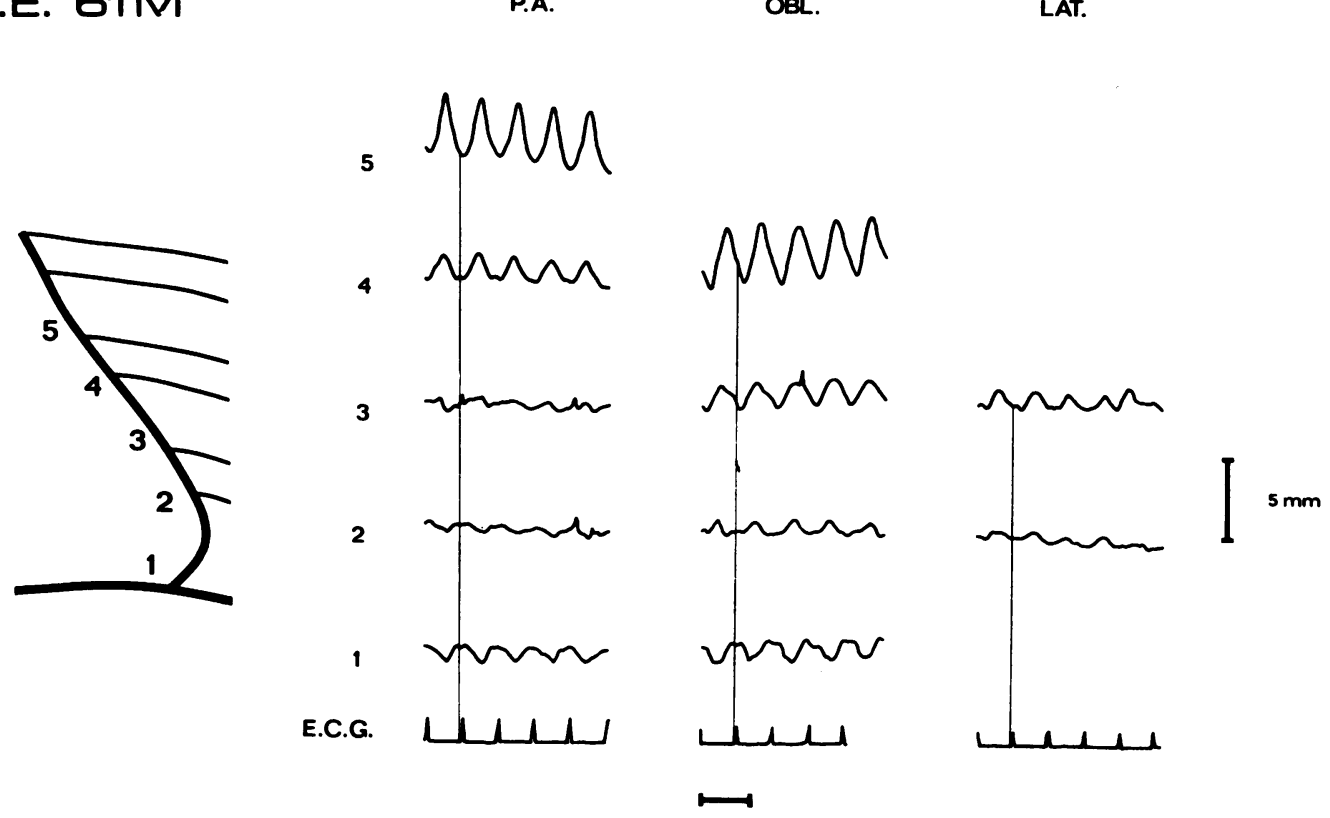

OBL.

LAT.

FIG. 5 Videogram of a patient with electrocardiographic evidence of anteroseptal infarction. Extensive hypokinetic and dyskinetic movement is evident, the latter shown as downward displacement of the traces during systole (positions $I$ and 2 in posteroanterior and oblique) indicated by an abnormal temporal relation of the movement to the electrocardiographic trace.

\section{Amplitude measurements}

Because of the incomplete information resulting from the technical limitations of the method in the lateral projection, only results from the posteroanterior and oblique projections have been analysed. In normal subjects in the posteroanterior projection there was, in general, a progressive increase in amplitude of displacement of the left ventricular margin from the apex towards the base of the heart (Fig. 7). Three observations indicated paradoxical (dyskinetic) activity in the lower lateral wall of the ventricle, two of them in one subject. As in the posteroanterior projection the observations in the normal subjects in the oblique projection displayed a wide range of displacements (Fig. 8), but in this projection no areas of dyskinesis were seen. Apart from the paradoxical areas in the posteroanterior projection, which are of considerable interest and will be discussed later, only 7 points of a total of II5 showed a displacement of less than $1.5 \mathrm{~mm}$ and this was arbitrarily designated the lower limit of normal.
The results obtained in the patients with myocardial infarction are also shown in Fig. 7 and 8. Though the range is again wide, a substantial number of measurements falls below the $1.5 \mathrm{~mm}$ level in both projections. Paradoxical activity presumed to be the result of severe myocardial damage is also seen in both projections. Statistical comparison of the means of the measurements in the 5 positions in the two groups shows no significant difference in the posteroanterior projection, but in the oblique the differences are significant $(P<0.005)$ in the central area of the posterolateral wall.

\section{Rates of systolic displacement}

The rates of displacement in the normal subjects and patients (Fig. 9 and 10) show a much narrower range of distribution at all positions than the amplitude measurements. The differences between the mean observations in the patients and normal subjects are again most obvious in the central part of the posterolateral aspect of the ventricle as seen in the oblique projection $(P<0.005)$. In these measure- 


\section{LATERAL \& INFERIOR INFARCTION}

\section{A.B. $54 \mathrm{M}$}

P.A.

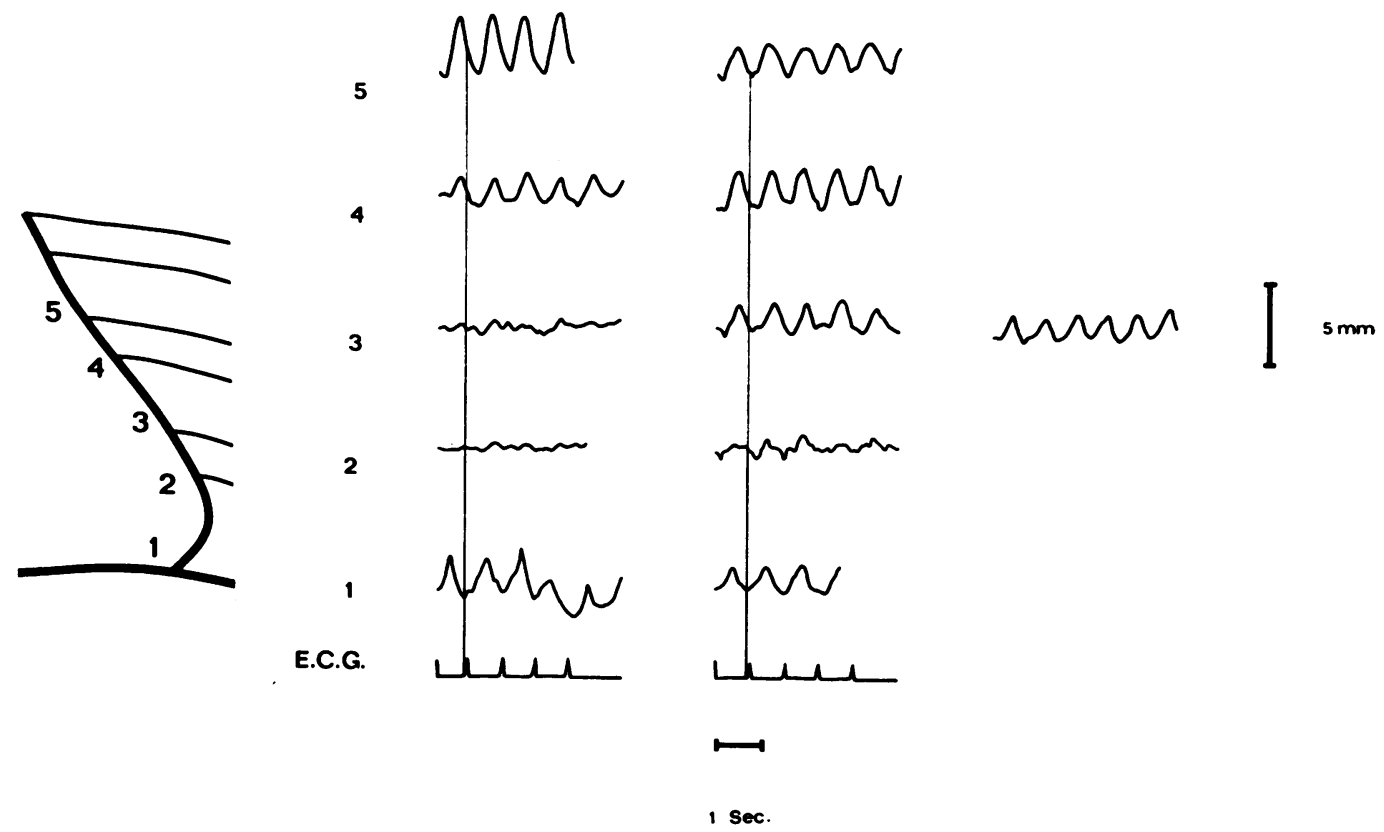

FIG. 6 Videogram of a patient with electrocardiographic evidence of lateral and inferior infarction showing areas of akinesis and hypokinesis.

ments the figure of $\mathrm{I} \cdot 0 \mathrm{~cm}$ per second has been taken as an arbitrary lower limit of normal, as only 8 points in the normal subjects fell below this level compared to more than half the observations in the abnormal group.

\section{Discussion}

Increasing interest in myocardial surgery has stimulated interest in methods of investigating areas of abnormal myocardial contraction. At the present time, left ventricular cineangiography is the most widely used method, but has inherent difficulties which limit its application. Alternative noninvasive methods of assessing left ventricular activity have included kinetocardiography, apex cardiography, and, more recently, ultrasonic cardiography, but none gives more than limited and very localized information. Videometry on the other hand enables the examination of a wide area of the left ventricular wall with no discomfort or hazard to the patient. Kazamias and his colleagues have illustrated the value of the technique using subjective analysis, and in our hands this approach has also been useful. However, preliminary attempts at quantitation suggest that more information may be obtained in this way. Arbitrary limits selected from the results of such a small group of subjects are liable to be altered with growing experience, but at the present time they are helpful guides in the rapid assessment of the infarction videogram.

The most striking differences between the normal subjects and the patients are seen in the oblique projection in both amplitude and rate of displacement measurements. The reason for this is uncertain. In this small series it may arise simply as this area of the ventricle is commonly affected by ischaemic injury. Alternatively, the arrangement of the circular muscle bundles in the myocardium described by Deliyannis and others (1964) may be relevant. Because of their circumferential course, ischaemic damage to them at any point would be likely to interfere with their overall constricting 
AMPLITUDE OF DISPLACEMENT OF LEFT HEART BORDER

( POST-ANT PROJECTION)

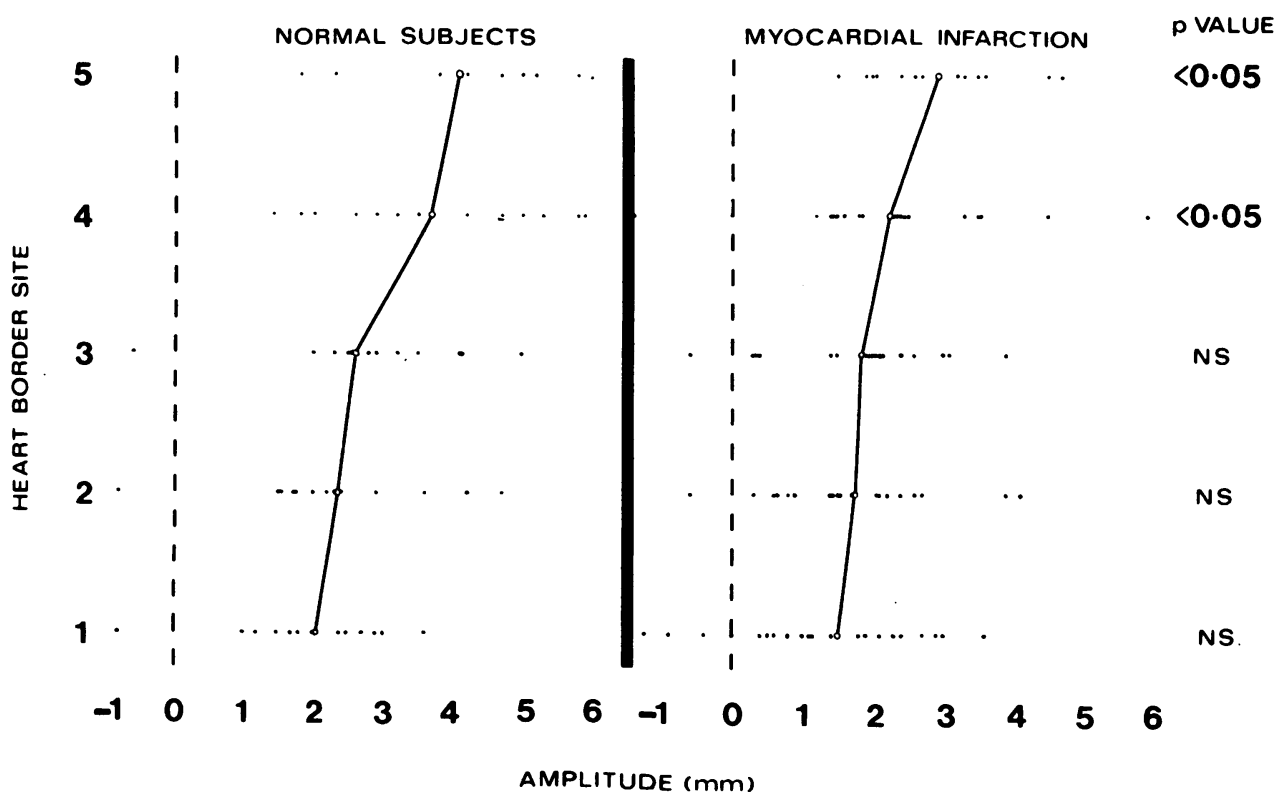

AMPLITUDE OF DISPLACEMENT OF LEFT HEART BORDER

(OBLIQUE PROJECTION)

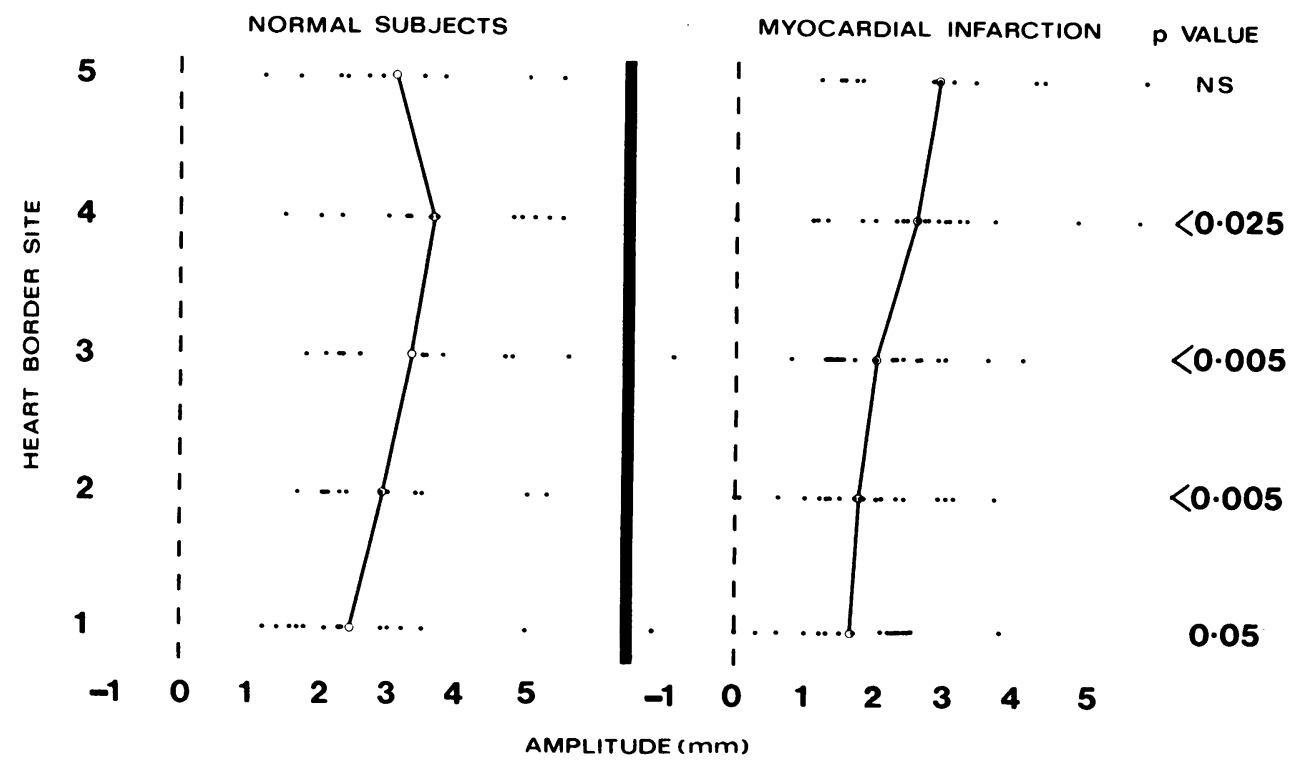

FIG. 7 and 8 Measurements of amplitude of displacement of left heart border in normal and abnormal subjects in posteroanterior and oblique projections (NS, not significant). 
RATE OF SYSTOLIC DISPLACEMENT OF LEFT HEART BORDER

(POST-ANT PROJECTION)

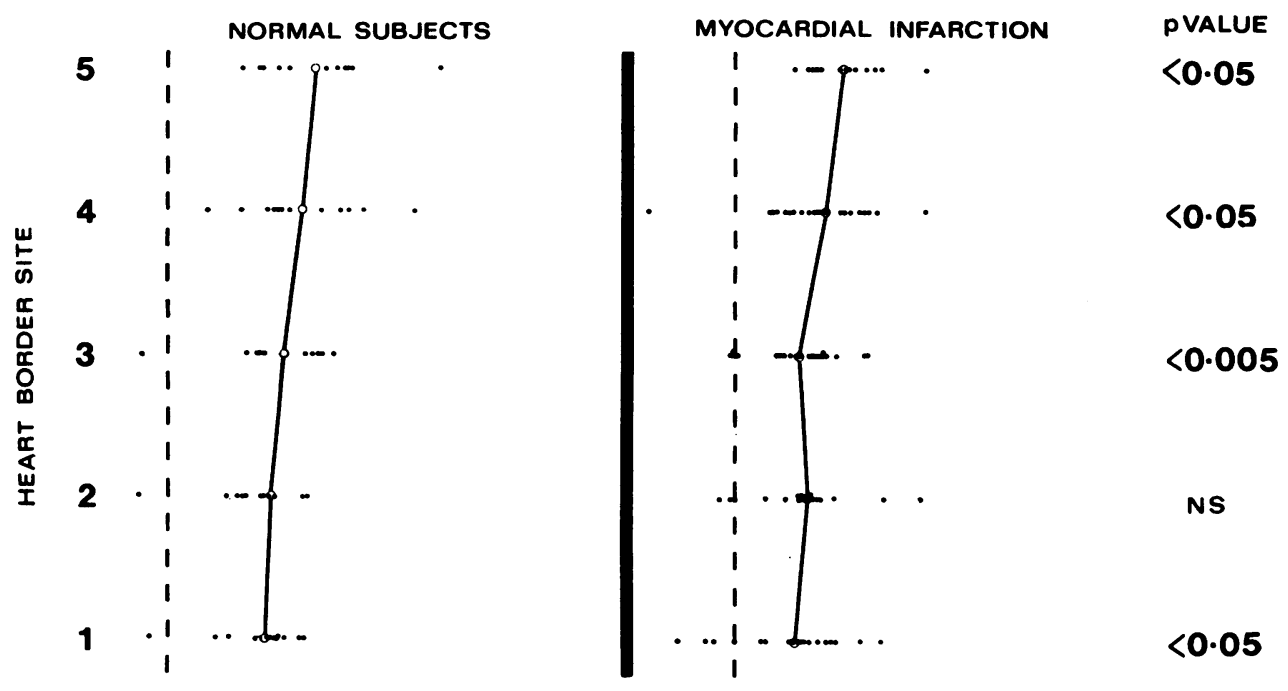

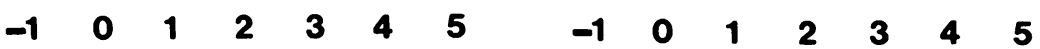
SYSTOLIC DISPLACEMENT RATE $(\mathrm{cm} / \mathrm{sec})$

RATE OF SYSTOLIC DISPLACEMENT OF LEFT HEART BORDER

(OBLIQUE PROJECTION)

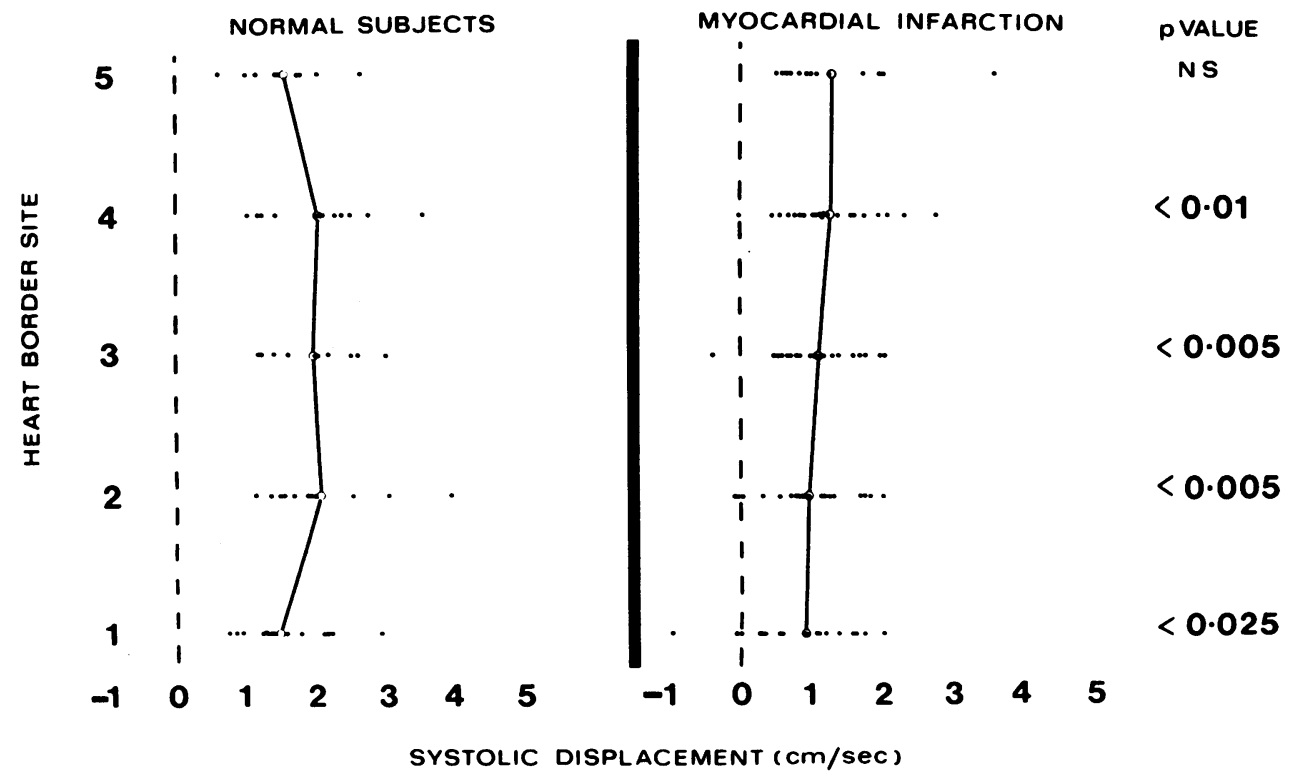

FIG. 9 and Io Measurements of rate of displacement of left heart border in normal and abnormal subjects in posteroanterior and oblique projections (NS, not significant). 
NORMAL

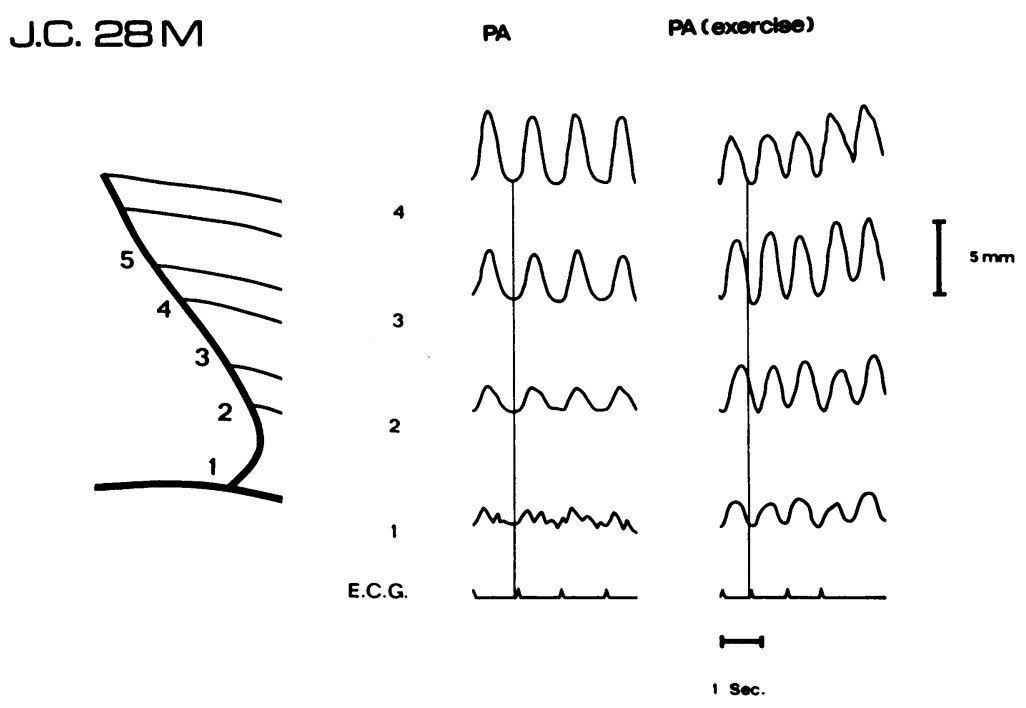

FIG. II Videogram of posteroanterior traces of left heart border movement before and during isometric leg exercise in a normal subject.

capability, and as the circular muscle predominates in forming the posterolateral $x$-ray silhouette of the heart, one might anticipate that abnormalities of contraction arising from local and distal myocardial injury would be most frequently seen in the oblique projection. The observation of dyskinetic movement in the apical area in two normal subjects is of considerable interest and importance as this type of abnormality must be distinguished from that due to severe coronary artery disease. Both subjects showing this change were athletic young men with no history of prior disease. Minor variations of the movement of the apical area of the ventricle have been reported previously (Sussman, Dack, and Master, 1940; Dack, 1955) but none appears to have been as obvious as the abnormalities which we have seen. In 1962, Keats and Martt reported paradoxical movement of the posterior wall of the left ventricle seen during fluoroscopy but attributed it to physiological factors induced by deep inspiration. However, in our subjects the appearances were evident at all levels of arrested respiration. In 1969, Herman and Gorlin suggested that the level of catecholamines in the myocardium might influence its contractility, and subsequently showed in two normal subjects (Helfant, Herman, and Gorlin, 197I) that propranolol caused akinesis in one and dyskinesis in the other. If one considers the situation where there is pre-existing parasympathetic dominance due to a high state of physical training and manifested in our two subjects by obvious bradycardia then one might anticipate that this state would produce a reduction in myocardial activity similar to the administration of propranolol, and that this might in turn be reversed by an increase in sympathetic tone. In order to test this hypothesis, a third normal subject (Fig. II) who presented with hypokinesis at the apex was studied at rest and then during a period of moderately severe isometric leg exercise (Donald et al., 1967). The exercise produced a brisk cardiovascular response associated with increase in heart rate from 56 to 80 per minute within the first is seconds of exercise. It is evident from Fig. II that the exercise has induced the return of normal contraction in the apical area. One would hardly wish to draw firm conclusions from a single experiment, but the results suggest that these normal subjects are illustrating the observations of Frick (1968) that physical training improves the efficiency of the myocardium producing changes in some ways similar to those caused by propranolol. In these fit men at rest it appears that the contraction of the apical area of the heart is 'not required' to maintain the cardiac output. It remains to be seen whether graded isometric 
exercise might be used to distinguish this type of muscular abnormality in normal subjects from that occurring in patients with severe coronary disease.

This preliminary study suggests that videometry may become a useful and valuable technique in the noninvasive investigation of patients suffering from severe myocardial disease, particularly in the monitoring of patients after infarction as a preliminary to myocardial surgery. However, precise correlation of the findings obtained by the technique with pathological data and established methods of assessment of myocardial function will be necessary to determine its place in patient management.

The authors wish to thank the physicians of the Southern General Hospital for referring the patients for investigation.

\section{References}

Bartley, O. (1960). Electrokymographic changes in myocardial infarction. Acta Radiologica, 54, 81 .

Cohen, L. S., Simon, A. L., Whitehouse, W. C., Schuette, W. H., and Braunwald, E. (1968). Heart motion videotracking (radarkymography) in diagnosis of congenital and acquired heart disease. American fournal of Cardiology, 22, 678.

Crawford, J. H., and Gubner, R. (1938). Roentgen kymographic studies in myocardial infarction (abstract). fournal of Clinical Investigation, 17, 507.

Dack, S. (I955). The ventricular pulsations in myocardial infarction: a fluoroscopic and kymographic study. Diseases of the Chest, 27, 282.

Dack, S., Sussman, M. L., and Master, A. M. (1940). The roentgenkymogram in myocardial infarction. II. Clinical and E.C.G. correlation. American Heart fournal, 19, 464.

Deliyannis, A. A., Gillam, P. M. S., Mounsey, J. P. D., and Steiner, R. E. (1964). The cardiac impulse and the motion of the heart. British Heart fournal, 26, 396.

Donald, K. W., Lind, A. R., Flue, D., McNicol, G. W., Humphreys, P. W., Taylor, S. H., and Staunton, H. P. (1967). Cardiovascular responses to sustained (static) contractions. Circulation Research, 20 and 21, Suppl. I, I5.
Frick, M. H. (1968). Coronary implications of hemodynamic changes caused by physical training. American fournal of Cardiology, 22, 417.

Gorlin, R., Klein, M. D., and Sullivan, J. M. (1967). Prospective correlative study of ventricular aneurysm. American Fournal of Medicine, 42, 512.

Gubner, R., and Crawford, J. H. (1939). Roentgenkymographic studies of myocardial infarction. American Heart Fournal, 18, 8.

Helfant, R. H., Herman, M. V., and Gorlin, R. (197I). Abnormalities of left ventricular contraction induced by beta adrenergic blockade. Circulation, 43, 64I.

Henny, G. C., and Boone, B. R. (1945). Electrokymograph for recording heart motion utilising the roentgenoscope. American fournal of Roentgenology, 54, 217.

Herman, M. V., and Gorlin, R. (1969). Implications of left ventricular asynergy. American fournal of Cardiology, 23, 538.

Herman, M. V., Heinle, R. A., Klein, M. D., and Gorlin, R. (1967). Localized disorders in myocardial contraction. New England fournal of Medicine, 277, 222.

Hirsch, I. S. (1934). The recording of cardiac movements and sounds by the roentgen ray. Radiology, 22, 403.

Kazamias, T. M., Gander, M. P., Ross, J., and Braunwald, E. (197I). Detection of left-ventricular-wall motion disorders in coronary-artery disease by radarkymography. New England fournal of Medicine, 285, 63.

Keats, T. E., and Martt, J. M. (1962). False paradoxic movement of the posterior wall of the left ventricle simulating myocardial aneurysm. Radiology, 78, 381.

Kurtzman, R. S., and Lofstrom, J. E. (I963). Detection and evaluation of myocardial infarction by image amplification and cinefluorography. Radiology, 81, 57 .

Master, A. M., Gubner, R., Dack, S., and Jaffe, H. L. (1940). Diagnosis of coronary occlusion and myocardial infarction by fluoroscopic examination. American Heart fournal, 20, 475.

Sussman, M. L., Dack, S., and Master, A. M. (1940). The roentgenkymogram in myocardial infarction. American Heart fournal, 19, 453.

Sussman, M. L., Dack, S., and Paley, D. H. (1949). Some clinical applications of electrokymography: the findings in myocardial infarction and heart block. Radiology, 53, 500 .

Requests for reprints to Dr. G. R. Sutherland, Department of Radiology, Southern General Hospital, Glasgow S.W.r. 